TITLE:

$<$ Article> Hunting attempt by chimpanzees on Abyssinian colobus at the Kalinzu Forest, Uganda

AUTHOR(S):

Ihobe, Hiroshi

CITATION:

Ihobe, Hiroshi. <Article> Hunting attempt by chimpanzees on

Abyssinian colobus at the Kalinzu Forest, Uganda. Pan Africa News 2001, 8(2): 31-32

ISSUE DATE:

2001-12

URL:

http://hdl.handle.net/2433/143397

RIGHT:

Copyright (c) Pan Africa News. 


\section{<ARTIGLE> \\ Hunting attempt by chimpanzees on Abyssinian colobus at the Kalinzu Forest, Uganda}

\author{
Hiroshi Thobe \\ School of Human Sciences, \\ Sugiyama Jogakuen University, \\ 37-234, Takenoyama, Iwasaki, Nisshin City, \\ Aichi, 470-0131, Japan
}

Since 1992, field studies on fauna and flora have been conducted at the Kalinzu Forest, Uganda, which is inhabited by six types of diurnal primates (1). Chimpanzees were observed to eat red-tailed monkeys (Cercopithecus ascanius) and blue monkeys (C. mitis), although no hunting was observed (2). This paper reports on the first observed case of an attempt to hunt monkeys by chimpanzees at Kalinzu.

\section{Observation}

A group of Abyssinian colobus (Colobus guereza), consisting of nine animals (two adult males, four adult females and three juveniles), was observed from September 1999 to January 2000. A hunting attempt by chimpanzees on this group occurred on 11 November. A party of 13 chimpanzees (five adult males, two adolescent males, four adult females, one juvenile, and one infant) tried to hunt the colobus.

At 7:33, I found the group of colobus. I heard the voices of chimpanzees from far away at
13:07, and they were within $200 \mathrm{~m}$ of the group at 14:44. The voice of a chimpanzee was heard within $100 \mathrm{~m}$ of the group at 14:57. I heard the voices of several chimpanzees near the group at 15:01, and an adult chimpanzee passed under a tree where the colobus rested. Another adult chimpanzee approached the group while pant-hooting and climbed a tree near the group. Another adult male chimpanzee climbed a Musanga tree where an adult male colobus was.

The adult male colobus silently ran around in the Musanga tree at 15:14. The adult male chimpanzee in the tree looked up at the colobus. Another adult male chimpanzee climbed it. I heard calls of several chimpanzees from $20 \mathrm{~m}$ away. The adult male colobus ran about again silently. Soon after, the waa-bark of about 10 chimpanzees was heard near the group.

An adult male chimpanzee climbed another tree where eight colobus rested at 15:27. The tree was $5 \mathrm{~m}$ away from the Musanga tree. Another adult male chimpanzee climbed it. An adolescent male chimpanzee moved to the tree where eight colobus were. Soon after, more than 10 chimpanzees gave waa-bark. An adult female colobus moved away from the tree. An adult male chimpanzee came to the tree where now seven colobus rested and chased an adult female colobus. She climbed down to the ground and ran away. An adult male colobus on the Musanga tree barked and chased the chimpanzee that had chased the colobus. The other adult male colobus and an adult female colobus chased the chimpanzee silently, and they climbed down to the ground and ran away. The chased chimpanzee also climbed down the tree. Several chimpanzees gave waa-bark. An adult male chimpanzee climbed the Musanga tree where an adult male colobus was. The colobus moved to the neighboring tree. Four chimpanzees sat around it. The chimpanzees gave waa-bark again. One of the four chimpanzees ran around in trees and broke a branch, and another chimpanzee screamed. The adult male colobus climbed down to the ground and ran away. Two or three chimpanzees also climbed down the tree and chased it. Four colobus immediately moved away in the trees. Only two adult male chimpanzees remained in the vicinity of the remaining female 
colobus.

The remaining colobus moved through trees at 15:39, and then no colobus remained. The voices of several chimpanzees were heard from $200 \mathrm{~m}$ away at 15:46 Soon after, the remaining two chimpanzees climbed down the trees. At 16:02, I found nine chimpanzees feeding on fruits of Ficus sp. about $300 \mathrm{~m}$ away from the site of the hunting attempt. No chimpanzee possessed a colobus. I finished observing them at 16:30.

No colobus was killed in this hunting attempt, because I observed nine colobus on 15 November.

\section{Discussion}

Chimpanzees at Kalinzu tried to hunt Abysinian colobus. Several chimpanzees, especially adult males, tried to hunt the colobus in the present case. Previous studies have revealed that several chimpanzees, especially adult males, frequently hunt red colobus (Procolobus badius) (3, 4). Chimpanzees at Kalinzu approached the colobus with vocalization, as did the chimpanzees at Mahale and Gombe (3, 4).

Abyssinian colobus at Kalinzu responded aggressively against the chimpanzees and chased them in the same way as the red colobus at Mahale and Gombe did $(4,5)$.

However, some differences were found between the case of red colobus hunting and the present case. The adult male Abyssinian colobus never made alarm calls against the chimpanzee approach, whereas the red colobus at Mahale and Gombe usually did $(5,6)$. The Abyssinian colobus at Kalinzu climbed down trees and moved on the ground despite the availability of continuous canopies, whereas the red colobus at Mahale and Gombe usually took escape routes in trees even in areas with broken canopies $(4,5)$. The Abyssinian colobus may adopt a "hide" strategy against chimpanzee hunters because of their small group sizes, so adult males never made alarm calls against a chimpanzee approach.

\section{Acknowledgements}

I thank the Uganda National Council for Science and Technology, the Uganda Forestry Department; and the Uganda Wildlife Authority for giving me research permission and assistance. This study was supported by a grant from the
Monbusho International Scientific Research Program (\#09041160 to T. Kano).

\section{References}

(1) Hashimoto C, Furuichi T, Tashiro Y, Kimura D 1999. Vegetation of the Kalinzu Forest, Uganda: Ordination of forest types using principal component analysis. African Study Monographs 20: 229-239.

(2) Hashimoto C, Furuichi T, Tashiro Y 2000. Ant dipping and meat eating by wild chimpanzees in the Kalinzu Forest, Uganda. Primates 41: 103-108.

(3) Goodall J 1986. The Chimpanzees of Gombe: Patterns of Behavior. Belknap Press, Cambridge, Mass.

(4) Hosaka K, Nishida T, Hamai M, Matsumoto-Oda A, Uehara S 2001. Predation of mammals by the chimpanzees of the Mahale Mountains, Tanzania. In: All Apes Great and Small, vol. 1: African Apes, Galdikas B, Briggs N, Sheeran L, Shapiro G (eds), Kluwer Academic Publishers, New York, in press.

(5) Stanford C 1998. Chimpanżee and Red Colobus: The Ecology of Predator and Prey. Harvard University Press, Cambridge, Mass.

(6) Thobe H 2000. Red colobus vs chimpanzees: Predator-prey relationships among primates. In: Primate Ecology, Sugiyama Y (ed), Kyoto University Press, Kyoto, pp: 61-84. (in Japanese) 